\title{
Contributions, topics, and methods
}

\author{
Antony Bryant ${ }^{1}$, Alistair Black ${ }^{2}$, Frank Land ${ }^{3}$, Jaana Porra ${ }^{4}$ \\ ${ }^{1}$ School of Computing and Creative Technologies, Leeds Metropolitan University, Leeds, UK; \\ ${ }^{2}$ Graduate School of Library and Information Science, University of Illinois, Urbana-Champaign, USA; \\ ${ }^{3}$ Information Systems and Innovation Group, London School of Economics, London, UK; \\ ${ }^{4}$ Department of Decision and Information Sciences, C.T. Bauer College of Business, University of Houston, Houston, USA
}

Journal of Information Technology (2013) 28, 91-92. doi:10.1057/jit.2013.9

I KEEP six honest serving-men

(They taught me all I knew);

Their names are What and Why and When

And How and Where and Who.

(Rudyard Kipling The Elephant's Child)

$\mathbf{T}$ he previous special issue of JIT (March 2013) comprised a set of papers on the history of IS, together with an extensive introductory essay by the editors (Bryant et al., 2013). The response to our Call for Papers on this topic was very encouraging, eliciting more than $20 \mathrm{com}$ pleted papers, from which 10 were selected for publication across two issues. The range of papers was such that, rather than dividing them in terms of content or topic, the five published in the March issue were those that were first to complete the cycle of review and revision. In this issue, we publish the remaining five.

The five presented in this issue cover a variety of topics, including two more papers that look at the development of the internet: Clarke taking a specifically Australian perspective, describing some of the earliest adopters in that region; Epstein offering an account of the ways in which the governance of the internet came to the centre of worldwide attention with the UN gatherings of World Summit on the Information Society I and II, and their aftermath. Between them, these papers illustrate the complex series of events that led to the current and still changing situation. This institutional perspective is also taken up in Elbanna and Newman's paper on the work of Enid Mumford, particularly the rise and demise of the ETHICS approach or method. They use Latour's Five Loop model as an explanatory framework, and Latour's work also forms a key resource for Bonner's analysis of the history of the Canadian personal motor vehicle registration (MVR) system in the form of Actor-Network Theory (ANT). Finally, Akhlaghpour and colleagues offer an account of the ways in which Orlikowski and Iacono's call for a focus on the 'IT Artifact' (or Artefact) has or has not been taken up in the main body of the US and European IS journals.

Overall, the 10 contributions cover a range of different topics, but some cover similar ground although from different perspectives. Thus, several deal with the internet as a central feature of their analyses but this is hardly surprising, given the ways in which the internet has developed since the 1960s, and particularly over the past 20-30 years. Akhlaghpour and colleagues discuss the ways in which the academic IS community has or has not taken up the quest for the IT Artifact, but there is surely a room for some irony in a widespread failure to recognize that perhaps the internet is the IT (or ICT) artefact par excellence, in which case the quest is already underway, and the metaphor can be extended to see the internet as a keystone of IS for academics, researchers, and practitioners. On the other hand, it has also become a key feature of many other disciplinary areas, and thus the challenge for IS researchers and academics generally is to stake a claim for conceptualizing specific issues around this technology, although as we stated in our earlier essay we are not advocating the idea of articulating some clear, central core for IS itself. Orlikowski and Iacono (2001) argued that IT was something of a spectre at the feast, but this is hardly the case with the internet since it appears to be constantly the centre of attention, either in its generic form or in terms of specific instantiations such as social networking, mobile technologies and applications, and the like.

No doubt, in time the internet will fade into the background, and future generations may well assume that the origins of the internet lie in one of the initial acts of creation, in which case historians of the future will need to offer accounts that bring the nature of these developments back into consideration. In a similar manner, the 10 papers in these two issues are largely motivated by a need to explain that specific aspects of what happened in the past need to be reinterpreted and taken into account for our current understanding of issues around IS. In this regard, Gannon's paper throws light on the early days of IT systems, recording people's recollections dating back to the 1960 s, offering an 'insider' view of how those early pioneers were viewed as 'outsiders' in a corporate world that now seems worlds apart from the organization of the early 21 st century. This raises the question of the extent to which IS people are still regarded as outsiders, and if so what the consequences might be of their outsider status. In our introductory essay in the previous issue, we made the point that one feature of historical analysis should be to explore the extent to which the familiar might appear strange, and the strange appear familiar. Gannon's paper does this by contrasting the early days of organizational computing with those experienced in more recent times. Heinrich and Riedl, on the other hand, focus on the development of something akin to IS, but from a perspective markedly different from the more common US- or UK-based contexts. In their account of what they term the Business 
Informatics community, they provide the basis for arguing that, within this German-speaking group, the orientation in favour of practice and design has been present and influential from the outset, thereby offering a contrast to the way in which the concept of design science has only recently come to the fore in other contexts.

The papers as a whole encompass different ideas about the nature of historical endeavours and also use a range of different methods. The papers by Campbell-Kelly and Garcia-Swartz, and by Jacobs, focus on technologies that for one reason or another failed to make the grade. Similarly, Clarke's account serves as a reminder that many of the offerings that developed around the growth of the internet in the 1970s-1990s now lie forgotten, buried in the wake of the current giants such as Google, Facebook, Twitter and so on. All three provide further evidence that the technologies that come to dominate often achieve this on the basis of a range of factors that go well beyond straightforward technical effectiveness; indeed, sometimes being technically better is no advantage at all.

Bonner and Epstein in different ways seek to ensure that historical analyses do not lose sight of the people involved in processes concerned with technical developments. Bonner uses Latour's ANT in his case study, and is concerned to bring to light the embodiment of the decision making that occurred in the evolution of the MVR system to the extent of locating the actual groups and individuals concerned. His paper to some extent reads like a detective novel, but a 'Who stored it?' rather than a 'Whodunnit?' Elbanna and Newman take up this feature of embodiment, although they do not refer to it as such in their focus on Enid Mumford. Without detracting from the importance of the individual as a 'mover' of history - an importance endorsed by the continuing effort of historians in producing historical biographies - 'The Great Man' approach to historical narrative, or even the Great Man or Woman approach, is now largely discredited or severely constrained; but if a secular IS pantheon were ever developed, Mumford would certainly figure prominently. Admittedly, the primary focus of Elbanna and Newman's paper is the ETHICS approach, rather than Enid Mumford; however, it is clear that a large degree of the success of ETHICS was because of her personality rather than Enid Mumford epitomized by her smile - and individual dynamism. Thus, even if the 'Great Man/Woman' hypothesis is rejected, the role of specific individuals as facilitators of change must still be encompassed and Mumford's role as a great facilitator certainly needs to be acknowledged.

The papers illustrate a diverse manner of 'doing IS history', encompassing chronology, narrative, institutional analyses, controversies, and disputes, characterizing epochs, focusing on neglected issues, and analysing disciplinary indicators such as key journals. Each of these has its particular strengths and weaknesses, and in some cases the contributors offer contending positions on historical writing and research; for instance, several authors offer characterizations of specific time periods or stages, while others argue that this is an invalid form of analysis and can lead to 'presentism' or what we referred to as the 'Whig interpretation of history' in our earlier essay. There is also a great diversity in the specific methods used, together with the justification for their implementation, as well as uses of materials and other resources. The methods used across the papers include case studies, interviews, analysis of published articles in indicative journals and other formally recognized outlets, use of generally available secondary sources, and web searches. This is far from exhaustive of the possible methods accessible to historians, but in part this is probably because of the relatively short time frame under consideration: most of the authors have experienced a good deal of this time period, and given their areas of expertise can be seen as participant observers to an extent. This yields historical accounts that are inevitably far less distant from the topic under consideration; in the future, histories of this period are bound to be markedly different.

All of these raise the question of what it is exactly that constitutes 'doing history'. Some have argued for there being a specifically historical method, but in the light of debates and critiques within and around the discipline of history this is an argument that is almost impossible to defend. However, the problem is that in relinquishing such claims, 'doing history' can lose its distinctiveness, merging imperceptibly with a host of related disciplines. Although there is certainly an argument to be made concerning the ways in which historians seek out and use the evidence they find and resources they use and then locate their findings and insights against specific contexts.

At this point, the quote from Kipling can finally be explained! All six of Kipling's 'serving-men' are important aspects of explanations and analyses, but for historians the order in which they are approached will usually place 'When' at the forefront, closely followed by 'What'. Depending on the motivation of the historian, attention may also centre around some or all of the other four, and as has already been pointed out some historical analyses place great emphasis on 'Who', arguably at the expense of other important factors. Note that this means that some histories do not primarily ask 'Why'.

This may appear to be a rather vague or weak characterization of 'doing history', but taken together with our paper in the previous issue we have sought to offer readers an appreciation of the wide range of approaches to history that are now extant. Moreover, we hope that, together with the 10 papers in these two issues, we have provided a set of materials that will encourage IS researchers to take account of IS history in their future efforts - or as Kipling put it in The Elephant's Child, will foster that 'satiable curtiosity'.

But there was one Elephant - a new Elephant - an Elephant's Child - who was full of 'satiable curtiosity, and that means he asked ever so many questions'.

\section{References}

Bryant, A., Black, A., Land, F. and Porra, J. (2013). Information Systems history: What is history? What is IS history? What IS history? ... and why even bother with history? Journal of Information Technology 28(1): 1-17.

Kipling, R. (1912). The Elephant's Child, from The Just So Stories available at [WWW document] http://www.online-literature.com/poe/165/ (accessed 12 February 2013).

Wanda, J., Orlikowski and Suzanne Iacono, C. (2001). Research Commentary: Desperately Seeking the "IT" in IT Research-A Call to Theorizing the IT Artifact, Information Systems Research 12(2): 121-134. 